\title{
Antibacterial effect of coconut water and coconut oil on Aggregatibacter actinomycetemcomitans
} Maryam Baharvand ${ }^{1}$,Mehdi Shokri ${ }^{2}$, Sarah Hassani ${ }^{3}$, Homa Mirzaei* (D), Mina Mahdian ${ }^{5}$

${ }^{1}$ Oral Medicine Dept. School of Dentistry, Shahid Beheshti University of Medical Sciences, Tehran, Iran. ${ }^{2}$ Department of Dental Biomaterials, School of Dentistry, Shahid Beheshti University of Medical Sciences, Tehran, Iran

${ }^{3}$ General Dental Practitioner, School of Dentistry, Shahid Beheshti University of Medical Sciences, Tehran, Iran

${ }^{4}$ Postgraduate student, Department of Oral Medicine, School of Dentistry, Shahid Beheshti University of Medical Sciences, Tehran, Iran.

${ }^{5}$ DDS, MDSc, Department of prosthodontics and Digital Technology, Stony Brook University, School of Dental Medicine, Stony Brook, NY, USA.

\begin{tabular}{l} 
ARTICLE INFO \\
\hline Article History \\
Received:May 2021 \\
Accepted: Apr 2021 \\
ePublished: June 2021 \\
Corresponding author: \\
Homa Mirzaei, ${ }^{4}$ Private \\
practice, Houston ,TX \\
Email: homamirzaei87@ \\
gmail.com
\end{tabular}

\section{Introduction}

Herbal medications have become an increasingly popular therapeutic alternative to synthetic medications amongst the general population. ${ }^{(1)}$ Coconut, with the scientific name of Cocos nucifera $\mathrm{L}$, has attracted the attention of scholars due to its abundance in tropical regions, low carbohydrate content, and antibacterial property. ${ }^{(2)}$ The anti-bacterial property of coconut is thought to be attributed to lauric acid, a fatty acid, that accounts for $50 \%$ of the fat content of the coconut. terial Agents

\begin{abstract}
Background and Aim:The antibacterial effects of coconut products have been extensively studied in the recent years. Due to the high prevalence of periodontal disease and the role of Aggregatibacter actinomycetemcomitans (A. actinomycetemcomitans) in periodontitis, antimicrobial agents can be effective in controlling this condition. This study aimed to evaluate and compare the antimicrobial effects of coconut water and coconut oil on A. actinomycetemcomitans.

Materials and Methods: Coconut water was extracted by cracking a coconut, and coconut oil was extracted by an oil-pressing machine by the cold pressing method at $-50{ }^{\circ} \mathrm{C}$. The disc diffusion test was carried out on 4 plates containing coconut oil, coconut water, positive control, and negative control to measure the diameter of growth inhibition zone. The minimum inhibitory concentration (MIC) and minimum bactericidal concentration (MBC) were determined. All tests were repeated 3 times. Results: Coconut oil in $100 \%$ concentration showed no antibacterial effect on A. actinomycetemcomitans in the disc diffusion test. Thus, the MBC and MIC were not determined for the coconut oil. Coconut water demonstrated a bactericidal effect with 11,9 , and $0 \mathrm{~mm}$ growth inhibition zone diameter on 3 consecutive repetitions. According to independent t-test, a significant difference existed between the diameter of growth inhibition zone caused by coconut oil and positive control $(\mathrm{P}=0.001)$. Conclusion: Coconut oil showed no antibacterial effect on A. actinomycetemcomitans, and the antibacterial effect of coconut water on A. actinomycetemcomitans was very weak.
\end{abstract}

J Res Dent Maxillofac Sci 2021;6(3):40-45.

Keywords: Aggregatibacter actinomycetemcomitans; Coconut Oil;Anti-Bac

Coconut products are available in various forms, two of which are coconut water and coconut oil. In vitro studies have documented the antibacterial effect of coconut oil on Streptococcus mutants and Candida species ${ }^{(3-5)}$, and coconut water on Candida albicans and Klebsiella pneumoniae ${ }^{(6)}$ Also, a control-free clinical trial showed that topical application of coconut oil led to a reduction in inflammation and plaque index in patients with plaque-free gingivitis. ${ }^{(7)}$ 
Periodontitis is one of the most common oral diseases ${ }^{(8)}$ affecting about $20-50 \%$ of the world's population..$^{(9)}$ Periodontitis develops and progresses due to the activity of a small group of generally Gram-negative and anaerobic bacteria that proliferate in the subgingival space; the three commonly involved pathogens include Porphyromonas gingivalis, Bacteroides forsythus, and Aggregatibacter actinomycetemcomitans (A. actinomycetemcomitans). ${ }^{(10)}$ Scaling and root planing with mechanical plaque control are known as the primary treatment for periodontitis. Nevertheless, many patients lose their teeth due to the related diseases despite successive dental visits. ${ }^{(1)}$ A. actinomycetemcomitans is a Gramnegative anaerobe that is associated with invasive localized periodontitis and is suspected to be involved in chronic periodontitis. It can defeat the immune system by producing a leukotoxin, a cell cycle-modifying protein, and it can also bond to the host's matrix and attack the cells. ${ }^{(12)}$ Considering the prolonged process and high costs associated with conventional periodontal therapy, it is prudent to consider effective and cheaper therapies. Therefore, topical antimicrobial agents have been studied as an alternative approach for treatment of periodontitis. ${ }^{(13)}$ To our knowledge, there are no in vitro studies on the effect of coconut products on oral pathogens other than Candida albicans and Streptococcus mutans. ${ }^{(3,5)}$ Considering that coconut water has been proven effective against Klebsiella pneumoniae, a Gram-negative bacterium ${ }^{(6)}$, as well as the important role of $\mathrm{A}$. actinomycetemcomitans, which is also a Gramnegative bacterium, in development of periodontal disease, and the availability and convenient application of coconut water as compared with its oil, we sought to investigate the antimicrobial effects of coconut water and coconut oil on $\mathrm{A}$. actinomycetemcomitans.

\section{Materials and Methods}

This in vitro study was approved by the ethics committee of Shahid Beheshti University of Medical Sciences (IR.SBMU.RIDS. REC.1396.581). The coconut used in this study was imported from Philippines. Due to the age of coconuts being unknown, we selected three coconuts and mixed their products. To extract coconut water, the coconuts were cracked and water was drained. Oil extraction was carried out at a temperature of $-50^{\circ} \mathrm{C}$ using a coconut oil extraction machine under a cold pressing process (Iran Cold Pressing Co., 35 caliber model, Iran). Coconut water and coconut oil were sterilized by a 0.2-micron syringe filter (bio file Co, Canada). The concentration of coconut water and coconut oil was $100 \%$.

A. actinomycetemcomitans colonies (JP2, Nov99) were transferred to $5 \mathrm{~mL}$ of brain heart infusion (BHI) broth (Merck Co., Germany). The tube containing the medium and bacteria was then placed in an incubator (Mmert Co, Germany) at $37^{\circ} \mathrm{C}$ in an anaerobic jar (Afshar equipment Co., Iran) for 72 hours using a Gas-Pak A (Anaerocult ${ }^{\mathrm{TM}} \mathrm{A}$; Merck Co., Germany) to allow the bacteria to proliferate and reach the desired concentration. Bacterial concentration was then analyzed by a spectrophotometer (Uniko Co., Germany) at $600 \mathrm{~nm}$ wavelength. The optical density to reach $0.5 \mathrm{McF}$ arland standard concentration should be equivalent to 0.08-0.1. Bacteria were subsequently collected by a loop and streakcultured on BHI agar medium (Merck Co., Germany) (Figure 1).

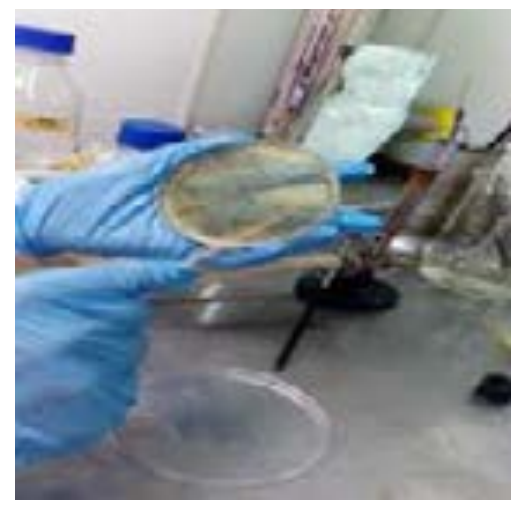

Figure 1: Streak-culture of bacte ria on $\mathrm{BHI}$ agar medium

\section{Agar-well diffusion assay:}

In the next step, the BHI broth agar medium was divided into four sections, and in each section, a well was created with $5 \mathrm{~mm}$ diameter and $5 \mathrm{~mm}$ depth in the agar using a sterile punch. The sections were allocated to coconut oil, coconut water, positive control $(0.2 \%$ chlorhexidine; NAJO Co., Iran), and negative control (saline; Merck Co, Germany) (Figure 2). 


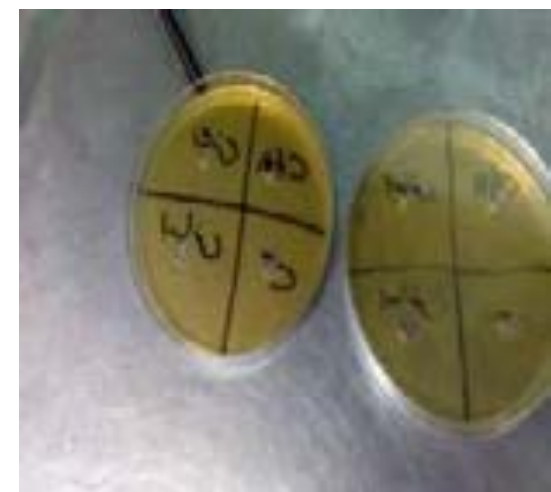

Figure 2: BHI agar medium prepared for the well-plate test

Coconut oil and coconut water were passed through a $0.2-\mu \mathrm{m}$ filter and poured into the respective wells using a sampler (Socorex Co., Switzerland) in an amount of $50 \mu \mathrm{L}$. The lids were then closed (Azarbin Co., Iran), and the plates were placed in an incubator as previously described. Upon removal of the plates from the incubator, it was observed that the coconut oil was not absorbed by the BHI agar medium. To mitigate this problem, the oil was dissolved by adding 2\% dimethyl sulfoxide (Carlo Erda Co, Spain) and 1\% ethanol (Bidestan Co, Iran), and the test was repeated. One section was allocated to the coconut oil, one section to saline, one section to the positive control, and one section to the negative control ( $2 \%$ dimethyl sulfoxide $+1 \%$ ethanol). The previous steps were then repeated, and the culture medium was placed in the anaerobic jar at the same temperature for 72 hours.

The antibacterial effect of coconut water on A. actinomycetemcomitans was tested following a similar procedure with the difference that coconut water was tested directly with no solvent. Each test was repeated three times, and the results were observed after 72 hours of incubation in an anaerobic jar. The antibacterial activity of each product was determined by comparing the diameter of growth inhibition zones with the diameter of the zone of growth inhibition formed around the chlorhexidine well.

\section{Minimum inhibitory concentration:}

To investigate the antibacterial effect of coconut water and coconut oil, the minimum inhibitory concentration (MIC) and minimum bactericidal concentration (MBC) were determined. MIC refers to the lowest concentration of antibacterial agent that inhibits visible growth of microorganisms after 48 hours of incubation, and MBC refers to the lowest concentration of an antibacterial agent that kills $99.99 \%$ of bacteria and indicates inability to be re-cultured.

To determine the MIC, the microdilution test and colorimetric methods were applied in a 96well plate consisting of 8 rows and 12 columns (SPL Co., Korea). One-hundred microliters of the BHI broth was poured into each well followed by $100 \mu \mathrm{L}$ of coconut water in the first well. Then, per serial dilution protocol, $100 \mu \mathrm{L}$ of the solution in the first well was collected by a sampler and poured into the second well, and this procedure was repeated until the concentration of the agent was reduced by 12 times (in the 12th well).

In the next step, $10 \mu \mathrm{L}$ of the $0.5 \mathrm{McF}$ arland standard bacterial suspension was added to all wells except the negative control row. The negative control, consisting of BHI broth medium, was poured into the wells of another row, and the positive control, which consisted of BHI broth medium and A. Actinomycetemcomitans, was poured into the wells of another row. All tests were repeated three times.

The plates were then incubated for 48 hours as previously described. Upon removal of the plates, $20 \mu \mathrm{L}$ of sterile $0.01 \%$ Resazurin dye (Sigma Co., USA) was added to all wells (Resazurin dye is revived under the influence of microbial activity and its color changes from blue to a purple hue). The discoloration was observed after 1-2 hours of incubation (Figure 3). The minimum concentration that showed no discoloration was considered as the MIC.

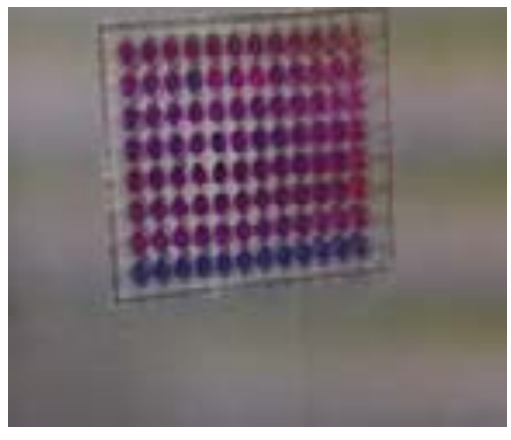

Figure 3: A 96-well plate after adding Resazurin dye 


\section{Statistical analysis:}

Data analysis was carried out using SPSS software version 21 (IBM Crop., Armonk, N.Y., USA). Statistical analysis was performed by independent t-test.

\section{Results}

The antimicrobial effect of the two coconut products (water and oil) on A. actinomycetemcomitans, is presented in Tables. Coconut oil $(100 \%$ concentration), added to the culture medium containing A. actinomycetemcomitans failed to exhibit any antibacterial effect and created no zone of inhibition (MIC mean $=0 \mathrm{~mm}$, standard deviation $=0$ ) compared with the positive control $(\mathrm{MIC}$ mean $=45 \mathrm{~mm}$, standard deviation $=4.08$ $\mathrm{mm}$ ); thus the MIC and MBC values were not reported for the coconut oil (Table 1).

Table 1: Effect of coconut oil on A. actinomycetemcomitans

\begin{tabular}{|c|c|c|c|}
\hline & $\begin{array}{c}\text { First } \\
\text { observation }\end{array}$ & $\begin{array}{l}\text { Second } \\
\text { repeat }\end{array}$ & $\begin{array}{l}\text { Third } \\
\text { repeat }\end{array}$ \\
\hline $\begin{array}{l}\text { Positive control: } \\
\text { chlorhexidine } \\
0.2 \%\end{array}$ & $\begin{array}{l}\text { inhibitory } \\
\text { zone diameter } \\
: 40 \mathrm{~mm}\end{array}$ & $\begin{array}{l}\text { inhibitory } \\
\text { zone } \\
\text { diameter: } 50 \\
\text { mm }\end{array}$ & $\begin{array}{l}\text { inhibitory } \\
\text { zone } \\
\text { diameter: } \\
45 \mathrm{~mm}\end{array}$ \\
\hline coconut oil & no effect & no effect & no effect \\
\hline $\begin{array}{l}\text { Negative control: } \\
\text { Saline }\end{array}$ & - & - & - \\
\hline $\begin{array}{l}\text { DMSO } 2 \%+ \\
\text { ethanol } 1 \%\end{array}$ & no effect & no effect & no effect \\
\hline
\end{tabular}

Coconut water $(100 \%$ concentration $)$ demonstrated an antibacterial effect on the culture medium containing A. actinomycetemcomitans with an average diameter of growth inhibition zone to be $6.6 \mathrm{~mm}$ (standard deviation $=4.78$ ). In MIC assessment, the concentration in the first well was diluted to $1 / 2$ of the concentration in the well plate test, and given the fact that in the well plate experiment, the results were very weak, no effects were observed in the MIC experiment. As a result, the MBC test was not carried out for the coconut water. The independent t-test showed a significant difference between the diameter of growth inhibition caused by coconut water and the positive control $(\mathrm{P}=0.001)$. (table 2$)$
Table 2: The effect of coconut water on the A.actinomycetemcomitans bacterium

\begin{tabular}{|c|c|c|c|}
\hline & $\begin{array}{l}\text { First } \\
\text { observation }\end{array}$ & $\begin{array}{l}\text { Second } \\
\text { repeat }\end{array}$ & Third repeat \\
\hline $\begin{array}{l}\text { Positive } \\
\text { control: } \\
\text { chlorhexidine } \\
0.2 \%\end{array}$ & $\begin{array}{l}\text { inhibitory } \text { zone } \\
\text { diameter }: 40 \\
\mathrm{~mm}\end{array}$ & $\begin{array}{lr}\text { inhibitory } & \text { zone } \\
\text { diameter: } & 50 \\
\mathrm{~mm} & \end{array}$ & $\begin{array}{l}\text { inhibitory zone } \\
\text { diameter: } 45 \mathrm{~mm}\end{array}$ \\
\hline Coconut water & $\begin{array}{l}\text { inhibitory zone } \\
\text { diameter }: 11 \mathrm{~mm}\end{array}$ & $\begin{array}{l}\text { inhibitory zone } \\
\text { diameter: } 9 \mathrm{~mm}\end{array}$ & no effect \\
\hline $\begin{array}{l}\text { Negative } \\
\text { control: Saline }\end{array}$ & - & - & - \\
\hline MIC & Not observed & Not observed & Not observed \\
\hline
\end{tabular}

\section{Discussion}

The majority of human periodontal conditions are caused by bacterial pathogens, and thus far, a wide range of antibacterial agents have been suggested to treat these conditions. Bacteria that are closely associated with the onset and progression of periodontal disease such as A. actinomycetemcomitans, Porphyromonas gingivalis, and Treponema denticola are called periodontopathic bacteria. ${ }^{(14)} \mathrm{A}$. actinomycetemcomitans and Porphyromonas gingivalis are two major periodontal pathogens. ${ }^{(15)} \mathrm{A}$. actinomycetemcomitans, which is an anaerobic microorganism, has been identified as a definitive pathogen in localized juvenile periodontitis, and periodontitis with rapid progression. Since A. actinomycetemcomitans has been identified as a periodontal pathogen in the subgingival plaque of many patients with periodontal disease ${ }^{(16-18)}$, it was used in the present study.

Coconut is predominantly a tropical fruit cultivated in countries such as the Philippines, India, Sri Lanka, Malaysia, and Indonesia and has been extensively used in the Asian traditional medicine for a long time. ${ }^{(19)}$

Coconut oil is used for cooking and in cosmetic products. This oil contains $92 \%$ saturated fatty acids, about $50 \%$ of which is lauric acid [4]. The antibacterial and antifungal effects of lauric acid have been previously confirmed. ${ }^{(19)}$ Coconut oil has a significant effect on Escherichia coli, Enterobacter species, Helicobacter pylori, Streptococcus mutans, Staphylococcus aureus, and Candida species. ${ }^{(5)}$ The precise mechanism of antibacterial activity of coconut oil is still unknown; however, it is postulated that monolaurin and several medium-chained fatty acids can bind to, penetrate into, 
and degrade the bacterial cell wall, and interfere with the enzymatic activity producing energy in the bacteria. ${ }^{(5)}$ The present study investigated the antimicrobial effect of coconut oil and water on A. actinomycetemcomitans.

According to the results of this study, the use of coconut oil ( $100 \%$ concentration) on A. actinomycetemcomitans in the microplates failed to produce any zone of inhibition, indicating that it did not have an antibacterial effect on this periodontal pathogen. As coconuts from different sources and with varying degrees of ripeness might show various antibacterial effects, negative results of coconut oil on A. actinomycetemcomitans may be due to the origin of the coconuts.

Nagila et al. ${ }^{(20)}$ found that the use of coconut oil significantly reduced the amount of bacterial plaque after 7 days of use in comparison with the control group. In most studies, coconut oil has been used as a mouthwash, and the improvement in periodontal conditions, which was observed in some studies, seems to be due to the reaction of salivary alkaline with oil and thus the formation of soap. This reaction reduces the binding probability of bacterial plaque to surfaces. ${ }^{(21)}$

According to studies by Beenashino et al, ${ }^{(4)}$ Peedikayil et al, ${ }^{(7)}$ and Ogbolu et al, ${ }^{(3)}$ coconut oil has an inhibitory effect on Candida albicans, Staphylococcus aureus, and Escherichia coli, which was inconsistent with the present results. This discrepancy may be due to the difference in the type of bacteria since A. actinomycetemcomitans which is a Gram-negative microorganism was evaluated in the present study.

Contrary to the aforementioned studies, Taheri et al. ${ }^{(2)}$ showed that coconut powder, similar to its oil, did not affect oral bacteria (there was no bacterial lysis zone in the plates), and in fact, did not show any antimicrobial activity against the oral bacterial flora. Their findings were in line with the findings of the present study. Ogbolu et al ${ }^{(3)}$ showed that coconut oil had antimicrobial effects on Candida, which is contrary to our study, likely due to differences in the type of microorganisms studied. Thaweboon et al. ${ }^{(5)}$ examined the effects of different types of oils such as corn oil, coconut oil, palm oil, sesame oil, sunflower oil, rice bran oil, and soybean oil on oral microorganisms. They found that coconut oil had an antibacterial effect on Streptococcus mutans and Candida albicans, which was inconsistent with the results of the present study. This difference can be due to the difference in the type of microorganisms studied. It was also concluded that sunflower and sesame oil decreased the count of Candida albicans and Streptococcus mutans, respectively. The difference between the abovementioned study and the present study in terms of effect on microorganisms could be due to the use of different oils. ${ }^{(5)}$

Beenashino et al, ${ }^{(4)}$ in an in vitro study compared the antibacterial activity of chlorhexidine, coconut oil, probiotics, and ketoconazole on Candida albicans in children who had early childhood caries. Their study confirmed the anti-microbial activity of coconut oil, which is contrary to the results of the present study. The reason for such discrepancy might be due to the difference in the type of microorganisms under investigation.

The results of the present study showed that coconut water $(100 \%$ concentration) had a growth inhibitory effect on A. actinomycetemcomitans, but it was not observed in the MIC test, and the antibacterial effect of the coconut water on A. actinomycetemcomitans was so minimal that was deemed clinically insignificant. As coconuts from different sources and with varying degrees of ripeness might show various antibacterial effects, negative results of coconut water on A. actinomycetemcomitans can be attributed to the origin of coconut.

Nasimuddin et al. ${ }^{(6)}$ investigated the antimicrobial activity of coconut water and oil on Gram-positive and Gram-negative bacteria including Staphylococcus aureus, Escherichia coli, Klebsiella pneumoniae, and Pseudomonas aeruginosa. The results showed that coconut oil and water had antibacterial properties; however, they did not affect Pseudomonas aeruginosa, which is inconsistent with the present study. Different results might be attributed to different types of bacteria (encapsulated Klebsiella) as well as the differences in testing conditions, such as type of culture medium, duration of effect, etc.

Rukmini et al. ${ }^{(22)}$ investigated the effect of coconut water on Streptococcus mutans and found that coconut water had no antibacterial effect on this microorganism, and no growth inhibitory effect was observed, which was inconsistent with the results of the present study. which may 
be due to different microorganisms studied and the Gram-negative nature of A. actinomycetemcomitans as compared with Streptococcus mutans.

Kohli et al. ${ }^{(23)}$ compared the antimicrobial susceptibility and cytotoxicity of coconut extract and chlorhexidine against Enterococcus faecalis, Prevotella intermedia, and Porphyromonas gingivalis. They observed that coconut extract had an antibacterial effect similar to that of chlorhexidine, which is contrary to coconut water and oil, as shown in the present study.

One of the limitations of the present study was that after removing the plates from the incubator, it was observed that the coconut oil had not been absorbed into the BHI agar medium, and to solve this problem, the oil was dissolved by adding $2 \%$ dimethyl sulfoxide and $1 \%$ ethanol and the test was repeated. The effect of coconut products on other oral pathogenic microorganisms should be investigated as well. In addition, the coconut used in the present study was from Philippines. Coconuts from other regions should be investigated in future studies.

\section{Conclusion}

Coconut oil did not have an antibacterial effect on A. actinomycetemcomitans, and coconut water also showed a poor antibacterial effect on A. actinomycetemcomitans.

\section{References}

1.Neville BW, Damm DD Allen CM, Chi AC. Oral and maxillofacial pathology. 4th edition, WB Saunders, Elsevier, Missouri, 2016;154-76.

2.Taheri JB, Espineli FW, Lu H, Asayesh M, Bakhshi M, Nakhostin MR, et al. Antimicrobial effect of coconut flour on oral microflora: An in vitro study. Res J Biol Sci. 2010;5(6):456-9. 3.Ogbolu DO, Oni AA, Daini OA, Oloko AP. In vitro antimicrobial properties of coconut oil on Candida species in Ibadan, Nigeria. J Med Food. 2007 Jun;10(2):384-7. doi: 10.1089/jmf.2006.1209.

4.Shino B, Peedikayil FC, Jaiprakash SR, Ahmed Bijapur G, Kottayi S, Jose D. Comparison of antimicrobial activity of chlorhexidine, coconut oil, Probiotics, and ketoconazole on Candida albicans isolated in children with early childhood caries: An in vitro study. Scientifica (Cairo). 2016;2016:7061587. doi: $10.1155 / 2016 / 7061587$.

5.Thaweboon S., Nakaparksin J, Thaweboon, B. Effect of oil-pulling on oral microorganisms in biofilm models. Asia J Public Health. 2011;2(2):62-6.

6. Nasimuddin S, Durai R, Sumathi G. A study of invitro antimicrobial activity of coconut water and coconut oil on gram positive and gram negative bacteria. World J Pharm Res. 2016;5(8):696-700.

http://www.jrdms.dentaliau.ac.ir
7. Ripari F, Filippone F, Zumbo G, Covello F, Zara F, Vozza I. The role of coconut oil in treating patients affected by plaque-induced gingivitis: A pilot study. Eur J Dent. 2020 Oct;14(4):558-565. doi: 10.1055/s-0040-1714194.

8. Raitapuro-Murray T, Molleson TI, Hughes FJ. The prevalence of periodontal disease in a Romano-British population c. 200-400 AD. Br Dent J. 2014 Oct;217(8):459-66.

9. Nazir MA. Prevalence of periodontal disease, its association with systemic diseases and prevention. Int J Health Sci. 2017;11(2):72-80.

10. Ardila CM, Bedoya-García JA. Antimicrobial resistance of Aggregatibacter actinomycetemcomitans, Porphyromonas gingivalis and Tannerella forsythia in periodontitis patients. J Glob Antimicrob Resist. 2020 Sep;22:215-218.

11. Michaud DS, Fu Z, Shi J, Chung M. Periodontal Disease, Tooth Loss, and Cancer Risk. Epidemiol Rev. 2017 Jan;39(1):49-58.

12. Henderson B, Ward JM, Ready D. Aggregatibacter (Actinobacillus) actinomycetemcomitans: a triple $\mathrm{A}$ * periodontopathogen? Periodontol 2000. 2010 Oct;54(1):78-105.

13. Sholapurkar A, Sharma D, Glass B, Miller C, Nimmo A, Jennings E. Professionally eldivered local antimicrobials in the treatment of patients with periodontitis-A narrative review. Dent J (Basel). 2020 Dec 22;9(1):2. doi: 10.3390/ dj9010002.

14. Socransky SS, Haffajee AD. Periodontal microbial ecology. Periodontol 2000. 2005;38:135-87. doi: 10.1111/j.16000757.2005.00107.x.

15. Scapoli L, Girardi A, Palmieri A, Testori T, Zuffetti F, Monguzzi R, et al. Microflora and periodontal disease. Dent Res J (Isfahan). 2012 Dec;9(Suppl 2):S202-6. doi: 10.4103/1735-3327.109755.

16. Chahboun H, Arnau MM, Herrera D, Sanz M, Ennibi OK. Bacterial profile of aggressive periodontitis in Morocco: a cross-sectional study. BMC Oral Health. 2015 Feb;15:25. doi: 10.1186/s12903-015-0006-x.

17. Monteiro Mde F, Casati MZ, Taiete T, Vale HF, Nociti FH Jr, Sallum EA, et al. Periodontal clinical and microbiological characteristics in healthy versus generalized aggressive periodontitis families. J Clin Periodontol. 2015 Oct;42(10):914-21. doi: 10.1111/jcpe. 12459.

18. Lovegrove JM. Dental plaque revisited: bacteria associated with periodontal disease. J N Z Soc Periodontol. 2004;(87):7-21.

19. Srivastava P, Durgaprasad S. Burn wound healing property of Cocos nucifera: An appraisal. Indian J Pharmacol. 2008 Aug;40(4):144-6. doi: 10.4103/0253-7613.43159.

20. Nagilla J, Kulkarni S, Madupu PR, Doshi D, Bandari SR, Srilatha A. Comparative evaluation of antiplaque efficacy of coconut oil pulling and a placebo, among dental college students: A randomized controlled trial. J Clin Diagn Res 2017;11(9):ZC08-ZC11.

21. Asokan S, Emmadi P, Chamundeswari R. Effect of oil pulling on plaque induced gingivitis: a randomized, controlled, triple-blind study. Indian J Dent Res. 2009 JanMar;20(1):47-51. doi: 10.4103/0970-9290.49067.

22. Rukmini JN, Manasa S, Rohini C, Sireesha LP, Ritu S, Umashankar GK. Antibacterial efficacy of tender coconut water (Cocos nucifera L) on Streptococcus mutans: An in-vitro study. J Int Soc Prev Community Dent. 2017 MarApr;7(2):130-134. doi: 10.4103/jispcd.JISPCD_275_16. 
23. Kohli D, Hugar SM, Bhat KG, Shah PP, Mundada MV, Badakar CM. Comparative evaluation of the antimicrobial susceptibility and cytotoxicity of husk extract of Cocos nucifera and chlorhexidine as irrigating solutions against Enterococcus Faecalis, Prevotella Intermedia and Porphyromonas Gingivalis - An in-vitro study. J Indian Soc Pedod Prev Dent. 2018 Apr-Jun;36(2):142-150. doi: 10.4103/JISPPD.JISPPD_1176_17

Cite this paper as:Baharvand M, Shokri M, Hassani S, Mirzaei H, Mahdian M. Antibacterial effect of coconut water and coconut oil on Aggregatibacter actinomycetemcomitans. J Res Dent Maxillofac Sci. $2021 ; 6$ (3) :40-45 